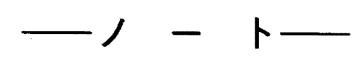

（日本化学会誌， 1994，（6)， p. 580～581）

(C) 1994 The Chemical Society of Japan

\title{
2-ビニル-8-キノリノールのラジカル重合とその 共重合物を配位子とする高分子銅錯体の合成
}

（1994年· 2 月21日受理）

米田昭夫*.白子忠男

\section{1 緒 言}

8-キノリノールは古くから知られている有機試薬で1), 多数の 金属と安定な錯体を形成する. 石炭液化油中にも含まれており2), その特性を利用した分子設計は炭素資源の有効利用の面から重要 である.しかしながら，電子供与体の窒素原子に隣接する 2 位 の置換基は錯体の安定性を下げる3). そこで, 2 位に(1)安定性を 减じないような置換基を導入する，(2)有用な反応に結びつくよう な置換基を導入する，などの工夫をすれば 8-キノリノール類の 新たな応用が期待出来る. (1)については, Corsini $5^{4)}$ の研究が ある. 本報では，(2)の観点から，2-ビニル-8-キノリノール(以 下, VQ と記す）を合成し，そのラジル重合性および銅錯体の 形成について検討した.

ビニル-8-キノリノールに関する報告は 3-ビニル体5)，5-ビニ ル体67)について見られる.ビニルキノリノールの特徵は分子に フェノール性 $\mathrm{OH}$ 基を有していることであり，一般には，ヒド ロキシスチレンタ)なとと類似したモノマーと考えられるが, 配位 子分子としての特性を考虑した実験を加える必要がある.

\section{2 実験方法}

VQは既報9)により合成した.モノマーは使用直前に蒸留して 用いた，過塩素酸銅（II）は試薬特級を使用し, キレート滴定法 により濃度を決定した.

VQの単独および共重合, ならびに錯体のラシカル重合は, 2,2 -アソビスイソブチロニトリル(AIBN) を開始剤としベンゼ ン溶液中, 窒素直换後减圧下に封管し $60^{\circ} \mathrm{C}$ の佰温漕中で行った. 重合物はベンゼンーメタノール系にて再沈精製した。

VQ と金属との錯体の合成は9)，それそれの50\%シオキサン溶 夜を室温下に混合した後, 約 $0.1 \mathrm{~mol} \cdot \mathrm{dm}^{-3}$ の水酸化ナトリウ 厶水溶夜を用いて $\mathrm{pH}$ を10以上にし，しばらくかきまぜた後生成 した着色沈殷を沪別し, 水でよく洗浄した後乾燥した.

\section{3 結果および考察}

$\mathrm{VQ}$ は分子中にビニル基とフェノール性 $\mathrm{OH}$ 基を有しているの でその重合性には関心が持たれる.そこで, $\mathrm{VQ}$ 濃度 $0.1 \mathrm{~mol} / l$ のベンゼン溶液中, AIBN を開始剤とし, 24 時間の単独重合を

姬路工業大学工学部応用化学科, 671-22 姬路市書写 2167
行った，得られた生成物は白色の沈殿（収率70\%) であり，その IR を図 1 に示した。モノマーのVQにおいて認められた 925 $\mathrm{cm}^{-1}$ のビニル基の吸収は生成物において消失した. $3400 \mathrm{~cm}^{-1}$ にはフェノール性 $\mathrm{OH}$ 基の吸収が存在している. 元素分析では, C 75.71; H 5.14; N 8.17\%の值が得られた. また, 分子量の測定 をVPO(KUNAUER 社蒸気圧测定装置, ベンジ標準物質)を 用い, THF を溶媒として行ったところ，643.6となった. 以上の 結果から, IR から重合の進行は認められるものの, 元素分析値 とVPO より重合度は三〜四量体となっていることが推定され た.これは，5-ビニル-8-キノリノール体や $p$-ビニルフェノール においてみられるのと同様に OH 基による重合抑制効果による むのと考えられる. しかし, これらのモノマーも共重合は進行す ることが報告されている6).そこでVQについてもスチレン (St), メタクリル酸メチル(MMA)および酢酸ビニルをそれぞれ 3 倍モル量加えて共重合を行った. いずれの場合にも, 精製後に フィルムとして得られ，十分高分子量に成長していることが推定 された. 因1にStとの共重合体のIR スペクトルを示した. $3370 \mathrm{~cm}^{-1}$ に OH 基による吸収が残り, $1230 \mathrm{~cm}^{-1}$ にはVQの 特性吸収がある. $1490,1462,1070,1015$ ，および $687 \mathrm{~cm}^{-1} に は$ スチレン単位に基ゔく吸収がみられる，そして，VQにおいてみ

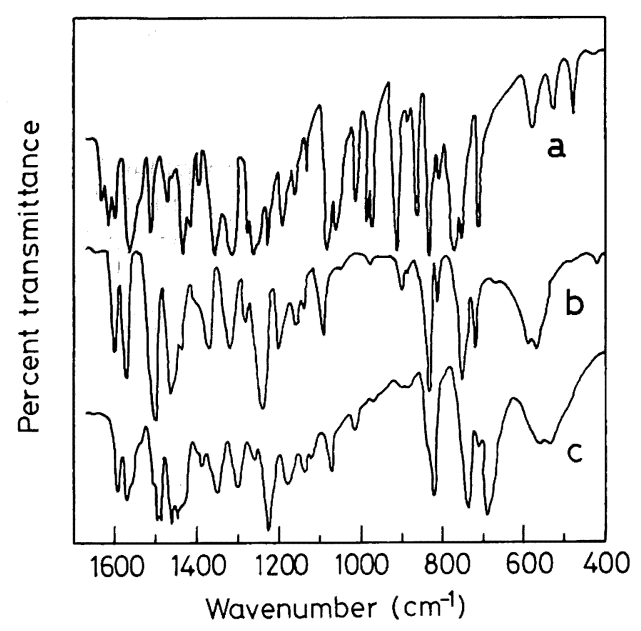

Fig. 1 IR spectra of $V Q$ (a), polymer (b) of $V Q$ and copolymer (c) of VQ-St. ( $\mathrm{KBr}$ pellet) 
られた $925 \mathrm{~cm}^{-1}$ のビニル基の吸収は完全に消失した. MMA， 酢酸ビニルとの共重合においても同様の挙動が認められた.

前述したように, キノリノールは電子対供与原子である $\mathrm{N}$ と O を有する二座配位子であり, 種々の金属と安定な錯体をつく る. 特に銅錯体は最も安定であることが知られている，そこで， $\mathrm{St}-\mathrm{VQ}$ 共重合体を用いて過塩素酸銅 (II) との反応を行いポリマ 一錯体の合成を試みた，得られた物質は暗草緑色をした固体であ った.

一方，VQ と銅との錯体の合成を試みた，反応はVQ と銅をそ れぞれ50\%ジオキサン中に調製しモル比が $2: 1$ となるように室 温で混合し, 溶液の $\mathrm{pH}$ が10以上になるようにして行った. 生成 した沈殿は濃い草緑色をしており，ほぼ定量的に得られた8). $\mathrm{mp}$ は $300^{\circ} \mathrm{C}$ 以上となり, 元素分析值は C $64.70 ; \mathrm{H} 3.68 ; \mathrm{N}$ $6.76 \%$ を示し，これは，2:1 錯体に対する計算值 $\left(\mathrm{C}_{22} \mathrm{H}_{16} \mathrm{~N}_{2} \mathrm{O}_{2}\right.$ $\mathrm{Cu} / 2 \mathrm{H}_{2} \mathrm{O}$ として) の C 64.00; $\mathrm{H} 4.15 ; \mathrm{N}$ 6.78に近い. ビス(2-ビ ニル-8-キノリノラート)銅 (II)の IR スペクトル(図 2) では, $\mathrm{VQ}$ の $3400 \mathrm{~cm}^{-1}$ の $\mathrm{OH}$ 基の吸収が消失し銅が 0 原子に配位し ていることを示した. また $925 \mathrm{~cm}^{-1}$ にはビニル基の吸収が認め られる.したがって，この錯体は重合抑制基の $\mathrm{OH}$ 基をもたな い二官能性のビニルモノマーとみなすことができる.すなわち， St と本錯体との共重合をすることによって前述の St-VQ 共重合 体を用いて，銅を添加しポリマー錯体を作製したものと類似の構 造の重合物が得られることになる. 実際ビス(2-ビニル-8-キ) リノラート)銅（II）錯体をスチレンに対して10分の $1 \mathrm{~mol}$ 加え,

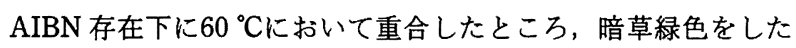
ポリマーが得られた、ベンゼンーメタノール系で再沈殿精製した 後にフィルムの作製を試みたところわずかに着色したきわめて破 れやすい透明な膜が得られた．そのIR スペクトルを図 2 に示 す. ポリスチレン単独フィルムの場合に比へて $1564,1482,1110$

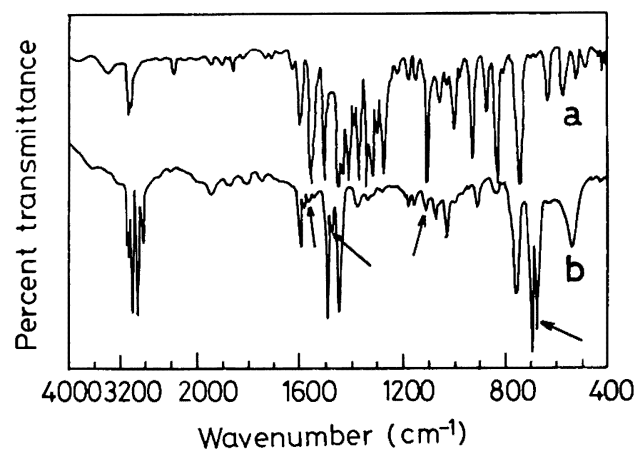

Fig. 2 IR spectra of $1: 2 \mathrm{Cu}-\mathrm{VQ}$ complex (a) (KBr pellet) and copolymer (b) of complex-St. (polymer film)

および $680 \mathrm{~cm}^{-1}$ に新たな吸収がみられた．前 3 者の吸収は，ビ ス(2-ビニル-8-キノリノラート)銅（II）錯体に由来するもので あり，VQ-St 共重合物と銅との反応により得られた高分子銅錯 体においても認められたものである.

1) W. D. Johnston, H. Freiser, J. Am. Chem. Soc., 74, 5239(1952).

2) M. Nishioka, R. M. Campbell, M. L. Lee, D. R. Muchiri, J. G. Stuart, R. N. Castle, Anal. Chem., 57, 2211(1985).

3) R. L. Stevenson, H. Freiser, Anal. Chem., 39, 1354(1967).

4) A. Corsini, R. M. Cassidy, Talanta, 26, 297 (1979).

5) F. C. Rauch, U. S. P., 3,615,889 (1971); Chem. Abstr., 76, $61043 \mathrm{~g}(1972)$.

6) V. G. Manecke, H. P. Aurich, Makromol. Chem., 133, 83(1970).

7) J. A. Buono, J. C. Buono, J. L. Fasching, Anal. Chem., 47, 1926(1975).

8) M. Kato, J. Polym. Sci., Polym. Chem. Ed., 7, 2175(1969).

9) A. Yoneda, T. Azumi., Chem. Lett., 1984, 1191.

\author{
Akio YoNEDA* and Tadao HAKUSHI \\ Department of Applied Chemistry, Faculty of Engineering, Himeji Institute of Technology; \\ 2167 Shosha, Himeji-shi 671-22 Japan
}

As polyligand souce, 2-vinyl-8-quinolinol(VQ) was prepared and polymerized at $60^{\circ} \mathrm{C}$ with $2,2^{\prime}-$ azobisisobutyronitrile (AIBN). Vapor pressure osmometric analysis indicated that the molecular weight of the resultant polymer was small. VQ was copolymerized with styrene, methyl methacrylate, and vinyl acetate. The copolymers formed complexes with copper(II) perchlorate. Similar polymer complexes were obtained in the copolymerization between bis (2-vinyl-8-quinolinolato) copper(II) and styrene. 